\title{
Araştırma Makalesi/Research Article (Original Paper) \\ Van Gölü Havzası Farklı Lokasyonlarından Alınan Ceviz Tohumlarında Çimlenme Sonrası Kök Kesimi Uygulamasının Çöğür Gelişimi Üzerine Etkisi
}

\author{
Adnan YAVİÇ, Adnan DOĞAN*, Ahmet KAZANKAYA, Tarık ENCÜ \\ Yüzüncü Yıl Üniversitesi, Ziraat Fakültesi, Bahçe Bitkileri Bölümü, Van, Türkiye \\ *e-posta: adnandogan@ @otmail.com
}

Özet: 2014-2015 y1lları arasında Yüzüncü Y1l Üniversitesi Ziraat Fakültesi Bahçe Bitkileri bölümüne ait üretim seralarında yürütülen bu araştırmada; materyal olarak Van Gölü havzasının farklı lokasyonlarından alınan ceviz tohumları kullanılmıştır. Sert kabuklu meyve türlerinden olan ceviz tohumlarında çimlenme sonrası kök kesimi uygulamasının ç̧öğür gelişimi üzerine etkilerini belirlemek amacıyla, denemede üç farklı uygulama (5 cm'den radisil kesimi, $7 \mathrm{~cm}$ 'den radisil kesimi ve kontrol) yapılmıştır. Köklendirme ortamından çimlenme sonrası sökülen ceviz çöğülerinin 1/3'ü radisil kesimi yapılmadan tüplere şaşırtılmış, 1/3'ü çimlenme ortamına tekrar dikilmiştir. Araştırmada, kontrol grubunda olan çöğürlerin genel olarak sürgün gelişimleri ile ilgili iyi performanslar gösterdiği, bununla birlikte $7 \mathrm{~cm}$ 'den radisil kesilen çöğülerde ise, kök ile ilgili gelişim parametrelerinin daha olumlu sonuçlar verdiği saptanmıştır. Çöğür performanslarında ceviz tohumun alındığı bölgenin de etkili olduğu belirlenmiştir.

Anahtar kelimeler: Ceviz, Çimlenme, Çöğür gelişimi, Kök kesimi, Radisil.

\section{Effect of The Application of Root Cutting After Germination on The Seedling Growth in The Walnut Seeds Taken From Van Lake Basin}

\begin{abstract}
This research was cunducted in production greenhouses of Yuzuncu Y1l University Agriculture Faculty Horticultural Crops Department during 2014-2015. Walnuts taken from various areas of Van Lake basin were used as research material. In order to determine the effects of the application of root cutting methods on walnut seedlings after germination three different applications were used (cutting of radicle from $5 \mathrm{~cm}$, cutting of radicle from $7 \mathrm{~cm}$ and control). One third of the walnuts which were ripped from the rooting area after germination have been planted without cutting the radicle and planted back to the germination area. The research revealed that the seedlings from control group performed well in shoot growth while the seedlings from $7 \mathrm{~cm}$ radicle cut group gave better results in the parameters about root development. The research also indicated that the area that welnut seeds were taken affected the seedling performences.
\end{abstract}

Keywords: Walnut, Germination, Seedling growth, Root cutting, Radicle.

\section{Giriș}

Meyve yetiştiriciliğinde, yetiştirilecek çeşit kadar anaçlar da oldukça önemlidir. Modern meyveciliğin önemli sorunlarından biri anaç seçimi ve çoğaltılmasıdır. Ceviz yetiştiriciliğinde henüz klonal anacın bulunmaması nedeniyle çögür anacı kullanımı zorunlu olmaktadır. Ülkemiz fidan üretiminde, tohumla anaç elde edilmesinin daha kolay olmasından dolayı çöğür anacı kullanımı birçok meyve türünde olduğu gibi ceviz için de geçerlidir (Koyuncu ve ark. 1999). Modern ceviz yetiştiriciliğinde kullanılan en pratik çoğaltma metodu aşı ile yapılan çoğaltmadır. Bu çoğaltma metodunun da birçok problemleri olmasına rağmen, halen yerini tutacak, daha pratik başka bir çoğaltma metodu olmadığı için, bu metottan faydalanılmaktadır (Şen ve ark. 2006). Ceviz yetiştiriciliğinde kullanılan anaçların hemen hepsinde bazı problemlerin görülmesinden dolayı diğer meyve türlerinde (Elma, Kiraz vb.) olduğu gibi cevizde de kabul görmüş bir anaç yoktur. Buna rağmen hala en çok geçerliliğini koruyan J. regia L. tohumlarından elde edilen anaçlardır (Sütyemez 2011). 
Birçok meyve türünde olduğu gibi ceviz yetiştiriciliğinde de tohumla çoğaltma metodu, genellikle anaç elde edilmesinde kullanılmaktadır. Tohum, iki ayrı bireyde veya aynı bireyin farklı organlarında oluşan erkek ve dişi gametlerin birleşerek, döllenmiş yumurtayı oluşturması ile meydana gelen ve ait olduğu bitkinin yeni bir bitki oluşturabilecek en küçük parçasıdır. Canlı bir tohumun meydana gelebilmesi için çiçek organlarının oluşması, daha sonra da tozlanma ve döllenmenin olması gerekir (Ăgaoğlu ve ark. 1997). Generatif yolla elde edilen bitkilerin istenilen özelliklerde meyve oluşturamaması gibi olumsuz yönlerinin yanında, kuvvetli bir kök sistemi oluşturmaları, bu bitkilerin başka amaçlarla değerlendirmesine yol açmıştır. Tohumdan elde edilen bitkiler (çöğür) anaç olarak kullanılarak, üzerine kalite bakımından istenilen özelliklere sahip bitkilerin aşılanması ile hem kalite, hem de kök sistemi bakımından üstün bitkiler elde edilebilmektedir (Alkan ve ark 2015).

Soğukta katlamanın amacı, dinlenme halindeki embriyoları çimlenme olgunluğuna getirmek ve tohum kabuklarının yapısını değiştirmektedir. Katlama, embriyoda bazı fizyolojik olaylara sebep olmakta ve tohumların çimlenme olgunluğuna gelmelerini sağlamaktadır (Kaşka ve Yılmaz 1974). Juglans türlerinin çoğunun cevizleri iyi bir çimlenme elde edebilmek için dikimden önce 3 ay kadar katlamaya alınmalıdır. İran cevizlerinin (J. regia L.) çimlenmesi için soğukta herhangi bir uygulama gerekli değilse de katlama çimlenmeyi hızlandırır. Juglans regia L. tohumlarının soğukta katlanması konusundaki çalışmalarda, soğukta katlanan tohumların katlanmadan ekilenlere göre 10-15 gün önce çimlendikleri belirlenmiştir.

Tohumların katlanması işlemi, mutlaka gerekli olan bir uygulama değildir. Şayet kış mevsimi çok kurak geçmiyor, yani toprak gerekli nemi ihtiva ediyor ve kış soğukları tohumların soğuklama ihtiyacını karşılamak için yeterli ise, tohumlar doğrudan doğruya toprağa ekilebilir. Bununla beraber, yapılan araştırmalara göre $2-8{ }^{\circ} \mathrm{C}$ 'de $2-4$ ay süre ile katlamaya tabi tutulan ceviz tohumları, katlama yapılmayan tohumlara göre belirgin şekilde fazla çimlenme göstermişler ve daha çok sayıda çöğür meydana getirmişlerdir (Şen ve ark. 2006).

Sert kabuklu meyve, türlerinde fidan üretim aşamaları, sırasıyla, ana bitkiden tohum alınması, tohumların katlamaya alınması, tohum ekimi, tohum çimlenmesi, çöğür gelişimi ve aşılamadır. Bu süreç izlenerek, tüplü veya çıplak köklü olarak fidanlar üretilebilir. Çıplak köklü fidan üretiminde, söküm sırasında kazık kökün zarar görmesi sonucunda, dikimi yapılan fidanlarda tutma oranının düşmesi nedeniyle, daha çok tüp içerisinde üretilmiş fidanlar tercih edilmektedir. Özellikle çalışma konusuna esas olan sert kabuklu meyve türlerinde, saçak kök gelişimi az olduğu ve kazık kök hâkimiyeti olduğu için, bunların fidanlıktan sökülmeleri sonucunda, kazık kökleri kesilmekte ve bu nedenle esas yerlerine dikildikten sonra, büyük oranda fidan tutum oranlarının düşük olduğu görülmektedir. $\mathrm{Bu}$ nedenle erken dönemde, tohum çimlenmesinden sonra kök ucu (radisil) kesimi yapılarak, saçak kök gelişiminin teşvik edilmesi ve buna bağlı olarak çögür gelişiminin ve fidan tutum randımanının arttırılması amacıyla bu çalışma planlanmıştır. Kök ucu kesimi ile saçak kök gelişimi teşvik edilmekte, çöğürlerin gövde çapları artmakta, çöğürlerin söküm işleri kolaylaşmakta, sökümden sonra canlı kalan çögür oranı artmakta ve fidanların bakımı kolaylaşmaktadır (Akça ve Yıldız, 1995). Çöğürlerin sökülmesi esnasında derinlere giden kazık köklerin kesilmesinden dolayı, çok kalın köklü olan ve yan kökleri bulunmayan çögürlerde, büyük yaralar açılmaktadır. Açılan bu yaralar nedeniyle, arazi koşullarına şaşırtılan fidanların tutma oranı düşmekte ve büyümeleri yavaşlamaktadır. Ayrıca hastalık ve zararlıların gelişmesi için, yaralı köklerde uygun ortam oluşmaktadır. Öte yandan, kazık köklü çöğürlerin sökülmesi çok zor olduğundan, söküm işlemi hem zaman almakta, hem de ek masraf getirmektedir (Akça ve Yıldız 1995). Çöğürlerin toprağın çok derinlerine giden kazık kök yapmalarını engellemek amacıyla, kök uçlarının şaşırtma sırasında kesilmesi gerekmektedir. Kök ucu kesiminin amaçları şu şekilde sıralanabilir; kazık kök gelişimini engellemek, saçak kök gelişimini teşvik etmek, çöğürlerin gövde uzunluğu ve çaplarını arttırmak (hızlandırmak), aşılanabilecek olgunluğa kısa sürede gelmelerini sağlamak, çöğürlerin söküm işlerini kolaylaştırmak, sökümden sonra canlı kalan çöğür yüzdesini arttırmaktır. Cevizde yapılan bir çalışmada, çimlenme boyunca radisil ve epikotilin boylamasına yarıya bölünmesi şeklinde yapılan teknikte, başarı oranı \% 90 olmuştur (Ko and Choi 1975).

Yapılan bu araştırmalardan yola çıkarak, sert kabuklu meyve türlerinden olan cevizin farklı lokasyonlardan alınan tohumlarında, çimlenme sonrası kök kesimi uygulamasının çögüü gelişimi üzerine lokasyonla birlikte etkilerini belirlemek amacıyla bu yürütülmüştür. 


\section{Materyal ve Yöntem}

Bu araştırma, Yüzüncü Yıl Üniversitesi Ziraat Fakültesi Bahçe Bitkileri bölümüne ait seralarında, 20152016 yılları arasında yürütülmüştür. Araştırmada materyal olarak farklı lokasyonlardan alınan ceviz tohumları (her lokasyonda bir ağaçtan alınmıştır) kullanılmıştır. Sert kabuklu meyve türlerinden ceviz tohumlarında, çimlenme sonrası kök kesimi uygulamalarının, çöğür gelişimi üzerine etkilerini belirlemek amacıyla yürütülen bu denemede; materyal olarak kullanılan ceviz tohumları Adilcevaz, Gevaş, Çatak, Bahçesaray ve Van (Merkez) ilçelerinden temin edilmiştir. Çalışmada bir örnekliği sağlamak amacıyla 8 g 'dan küçük cevizler kullanılmamıştır. Ceviz tohumları ekilmeden önce, 24 saat suda bekletilmiştir. Su üzerine çıkan tohumlar ekimde kullanılmamıştır. Ceviz tohumları 14 Ekim 2015 tarihinde, toplam 4500 tane olacak şekilde ekilmiştir. Deneme tesadüf blokları deneme desenine göre, 5 tekerrürlü olarak kurulmuştur. Her tekerrürde 60 'şar tane tohum ekimi yapılmıştır. Tohumlar kendi boylarının yaklaşık üç katı derinlikte olacak şekilde, perlit ortamına ekilmiştir. Daha sonra, iki haftada bir çimlenen tohumlar sayılarak kaydedilmiştir. Denemede kullanılan cevizlere ait çimlenen tohumlardan elde edilen çöğürlerde, üç farklı uygulama yapılmıştır. Bunlar; radisil kesimi yapılmayan grup (kontrol grubu), $5 \mathrm{~cm}$ 'den radisil kesimi yapılan grup ve $7 \mathrm{~cm}$ 'den radisil kesimi yapılan gruptur. Çimlenme ortamından sökülen farklı lokasyon kaynaklı ceviz çögürlerinin 1/3'ü radisil kesimi yapılmadan ve 1/3'ü radisil kesimi yapılarak tüplere, diğer 1/3'ü ise kök gelişim parametrelerini takip etmek amaçlı çimlenme ortamına uygulamalar yapıldıktan sonra tekrar dikimi gerçekleştirilmiştir.

Uygulamalar farklı lokasyonlardan alınan perlit ortamında çimlendirilen çögürler söküldükten sonra, ceviz tohumdan ilk çıkan kotiledon yaprakların bulunduğu yerin altından, ilk $5 \mathrm{~cm}$ ve $7 \mathrm{~cm}$ 'lik kök kısmı bırakılarak kesim gerçekleştirilmiştir. Yapılan uygulamalar sonrasında, çöğürlerin 1/3'ü tüplere aktarılmıştır. Tüplere aktarılan çöğürler için kullanılan harç; 1/4 bahçe toprağı, 1/4 dere kumu, 1/4 perlit, 1/4 yanmış hayvan gübresi içermektedir. Harç tüplere konulmadan önce yeteri kadar nemlendirilmiştir. Tüpler, şaşırtma öncesi bir miktar harç ile doldurulduktan sonra, uygulamaların yapılacağı çöğürler, çimlenme ortamından sökülmüştür. Her tekerrürde bulunan her lokasyona, 3 farklı uygulama yapılmıştır. Alınan çöğürlerin 1/3'ünün kökleri $5 \mathrm{~cm}$ 'den, 1/3'ünün $7 \mathrm{~cm}$ 'den kesilerek, 1/3'ün de kesim yapılmadan kontrol grubu olarak tüplere şaşırtılmıştır. Uygulama sonrasında tüplere aktarılan çöğürlerde, şaşırtma sonrasında kayıplar meydana gelmiştir. Bu çöğürlerde, canlı kalan çöğür sayısına bağlı olarak, kayıp oranları (\%) belirlenmiştir. Denemeye canlı kalan tüplü çöğürler ile devam edilmiştir. Çöğürlere yapılan radisil kesimi sonrasında, türler bazında, çögürlerin 1/3'ü tekrar çimlenme ortamına dikilmiştir. Bu çögürlerde, radisil kesimi uygulamasının, kök gelişimi üzerine etkilerinin belirlenmesi amaçlanmıştır. Denemede kullanılan cevizlere uygulanan radisil kesim işlemleri yapılarak, deneme sonunda ilgili parametreler saptanmıştır. Radisil kesimi uygulamaları sonrası 1/3 tüplere aktarılan çöğürlerde, sürgün gelişimi ile ilgili olarak, gövde uzunluğu $(\mathrm{cm})$, gövde çap1 $(\mathrm{mm})$, ve yaprak sayısı (adet) belirlenmiştir.

Radisil kesimi yapılarak tekrar çimlenme ortamına dikilen çöğürlerde ise, kök ve gövde gelişim parametreleri incelenmiştir. Uygulamaların çöğürlerde kök gelişimlerine etkilerini belirlemek amacıyla; gövde uzunluğu (cm), saçak kök sayısı (adet), en uzun saçak kökün uzunluğu (cm), kök çapı (mm) ve yaprak sayısı (adet) gibi parametreler saptanmıştır.

Verilerin değerlendirilmesi ceviz tohumlarında, çimlenme sonrası kök kesimi uygulamasının ve farklı lokasyonların çögür gelişimi üzerine etkilerini belirlemek amacıyla elde edilen verilerde, STAT GRAPHICS istatistiksel analiz programı kullanılarak varyans analizi yapılmıştır. Ortalamalar arasındaki farklılıklar, LSD karşılaştırma testi $(\mathrm{p}<0.05)$ ile belirlenmiştir

\section{Bulgular}

Tohum çimlenmesi ile ilgili bulgular 14 Ekim 2015 tarihinde ekimi gerçekleştirilen ceviz tohumlarının ekim tarihinden itibaren 65 gün sonra çimlenmeye başlamıştır. En son yapılan 98 gün sonra sayımlara göre, toplamda 3684 tohumun çimlendiği ve ortalama çimlenme oranının \% 81,88 olduğu saptanmıştır (Çizelge 1.). Tüm kayıplar yaşandıktan sonra tekerrürde 15 bitki kalacak şekilde deneme revize edilmiştir. 
Çizelge 1. Denemede kullanılan tohumların tekerrürlere göre ortalama çimlenme oranları (\%)

\begin{tabular}{lc}
\hline Lokasyonlar & Çimlenme Oranı (\%) \\
\hline 1- Adilcevaz & 85,2 \\
2- Gevaş & 83,6 \\
3- Çatak & 78,7 \\
4- Bahçesaray & 79,5 \\
5- Van (Merkez) & 82,4 \\
\hline Ortalama & $\mathbf{8 1 , 8 8}$ \\
\hline
\end{tabular}

Radisil kesimi sonrası tüplere aktarılan çöğürler ile ilgili bulgular Radisil kesim uygulamaları sonrası, tüplere aktarılan çöğürlerde meydana gelen kayıplar nedeniyle, elde edilen çöğür sayısında azalma meydana gelmiştir. Bu kayıpların türlere göre değiştiği Çizelge 2'de belirtilmiştir. Ceviz çögürlerinde, şaşırtma sonrası kayıp en fazla 7 cm'den radisil kesimi yapılan çögürlerde görülmüştür. Kontrol grubu çögürlerde görülen kaybın ise en düşük düzeyde olduğu saptanmıştır. Uygulamalar sonrası çögürlere ait bazı parametre ölçümleri yapıldıktan sonra, bu parametrelere ait veriler ile STAT GRAPHICS istatistiksel analiz programı kullanılarak varyans analizi yapılmıştır. Ortalamalar arasındaki farklılıklar, LSD karşılaştırma testi $(\mathrm{p}<0.05)$ ile belirlenmiştir.

Çizelge 2. Denemede kullanılan çöğürlerde şaşırtma sonrası meydana gelen kayıp oranları

\begin{tabular}{lccc}
\hline \multirow{2}{*}{ Lokasyonlar } & \multicolumn{3}{c}{ Şaşırtma Sonrası Kayı Oranı (\%) } \\
& Kontrol & $\mathbf{5} \mathbf{~ c m} \mathbf{d e n}$ Kesim & $\mathbf{7} \mathbf{~ c m} \mathbf{d e n}$ Kesim \\
\hline 1- Adilcevaz & 1,54 & 2,16 & 2,65 \\
2- Gevaş & 1,16 & 1,94 & 2,10 \\
3- Çatak & 1,92 & 2,72 & 3,10 \\
4- Bahçesaray & 2,05 & 2,76 & 3,21 \\
5- Van (Merkez) & 1,2 & 2,25 & 2,87 \\
\hline Ortalama & $\mathbf{1 , 6 7}$ & $\mathbf{2 , 4 0}$ & $\mathbf{2 , 7 7}$ \\
\hline
\end{tabular}

Gövde Çapı

Yapılan çalışmada deneme faktörlerinden lokasyon, uygulamalar ve lokasyon/uygulama interaksiyonlarının gövde çapı oranları üzerine etkileri istatistiksel olarak önemli olduğu belirlenmiştir $(\mathrm{P}<0.05)$. En yüksek gövde çapı Adilcevaz ve Van (merkez) yöresine ait cevizlerden elde edilmiştir $(9,22-9,07)$. Uygulamaların gövde çapı oranı üzerine en olumlu sonucu 9,20 mm ile kontrol uygulaması olmuş onu radisilin $7 \mathrm{~cm}$ 'den kesimi uygulaması 8,81 $\mathrm{mm}$ ile takip etmiştir. Lokasyon ve uygulama interaksiyonunda Adilcevaz+kontrol 10,07 mm değeri ile öne çıkmıştır. Her bir uygulamanın kendi içinde ortaya koymuş olduğu performans Çizelge 3 ve Şekil 1'de sunulmuştur. Gövde Çapı üzerinde lokasyonlar açısından Adilcevaz ve Van (Merkez), uygulamalar açısından Kontrol grubu öne çıkmıştır.

Çizelge 3. Lokasyon ve Uygulamalara göre Gövde Çapı $(\mathrm{mm})$ oranları

\begin{tabular}{|c|c|c|c|c|}
\hline Lokasyonlar & Kontrol & $\begin{array}{c}\text { Uygulamalar } \\
5 \text { cm'den Kesim }\end{array}$ & 7 cm'den Kesim & Ortalama \\
\hline 1-Adilcevaz & 10,07 & 8,33 & 9,27 & $9,22 \mathrm{a}$ \\
\hline 2- Gevaş & 9,42 & 7,57 & 8,98 & 8,66 ab \\
\hline 3-Çatak & 9,07 & 7,68 & 9,16 & 8,64 ab \\
\hline 4-Bahçesaray & 7,99 & 8,24 & 8,76 & 8,33 b \\
\hline 5-Van (Merkez) & 9,44 & 9,92 & 7,86 & 9,07 a \\
\hline Ortalama & $9,20 \mathrm{a}$ & 8,35 b & 8,81 ab & 8,78 \\
\hline
\end{tabular}

*Her bölüm içinde aynı harfi gösteren ortalamalar arasındaki fark önemli değildir $(\mathrm{p}<0.05)$. 
Interactions and 95,0 Percent LSD Intervals

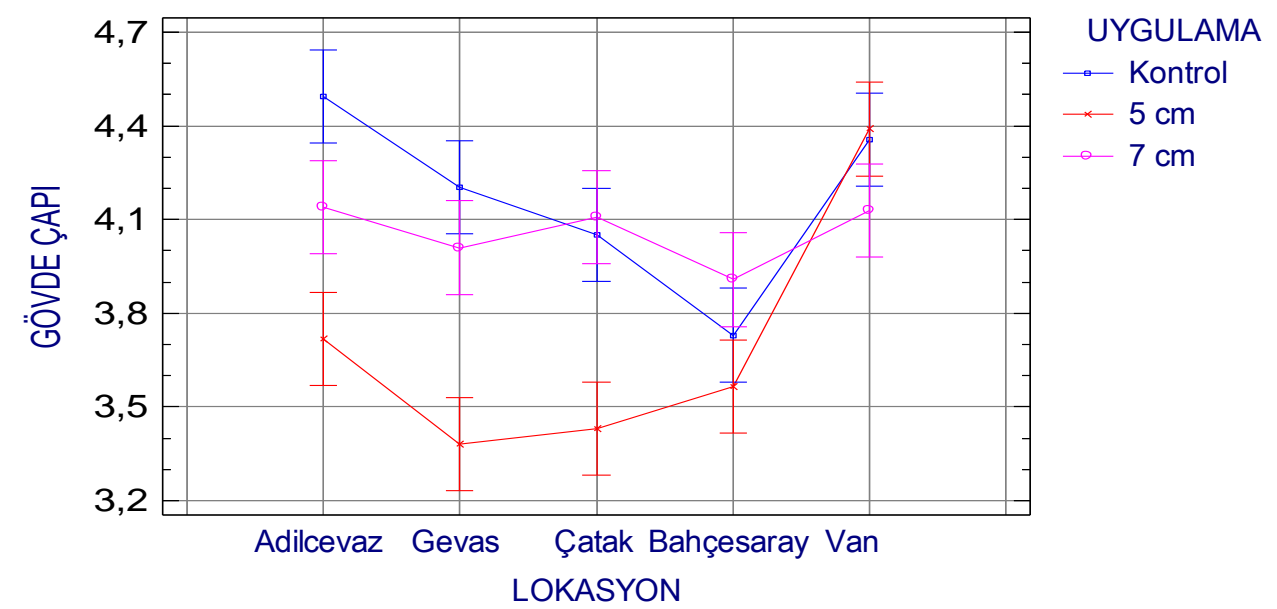

Şekil 1. Lokasyon ve Uygulamalara göre Gövde Çapı (mm) oranları

Sürgün Boyu

Yapılan çalışmada deneme faktörlerinden lokasyon, uygulamalar ve lokasyon/uygulama interaksiyonlarının sürgün boyu oranları üzerine etkileri istatistiksel olarak önemli olduğu belirlenmiş̧ir $(\mathrm{P}<0.05)$. En yüksek gövde çapı Van (merkez) ve Bahçesaray yöresine ait cevizlerden elde edilmiştir $(18,19-17,64 \mathrm{~cm})$. Uygulamaların gövde çapı oranı üzerine en olumlu sonucu 17,62-16,37 cm ile kontrol ve radisilin $5 \mathrm{~cm}$ 'den kesimi uygulaması olmuştur. Lokasyon ve uygulama interaksiyonunda Bahçesaray+kontrol ve Van (merkez) +kontrol 20,08 cm değeri ile öne çıkmıştır. Her bir uygulamanın kendi içinde ortaya koymuş olduğu performans Çizelge 4 ve Şekil 2'de sunulmuştur. Gövde Çapı üzerinde lokasyonlar açısından Van (Merkez) ve Bahçesaray, uygulamalar açısından Kontrol ve $5 \mathrm{~cm}$ kök kesimi yapılan grup öne çıkmıştır.

Çizelge 4. Lokasyon ve Uygulamalara göre Sürgün Boyu (cm) oranları

\begin{tabular}{lcccc}
\hline \multicolumn{1}{c}{ Lokasyonlar } & Kontrol & $\begin{array}{c}\text { Uygulamalar } \\
\mathbf{5} \text { cm'den Kesim }\end{array}$ & $\mathbf{7} \mathbf{c m}$ den Kesim & Ortalama \\
\hline 1-Adilcevaz & 18,55 & 16,73 & 13,90 & $\mathbf{1 6 , 3 9} \mathbf{b}$ \\
2- Gevaş & 14,28 & 14,70 & 12,90 & $\mathbf{1 3 , 9 6} \mathbf{c}$ \\
3-Çatak & 15,10 & 14,53 & 13,58 & $\mathbf{1 4 , 4 0} \mathbf{c}$ \\
4-Bahçesaray & 20,08 & 18,45 & 14,40 & $\mathbf{1 7 , 6 4}$ a \\
5-Van (Merkez) & 20,08 & 17,43 & 17,08 & $\mathbf{1 8 , 1 9}$ a \\
\hline \multicolumn{1}{c}{ Ortalama } & $\mathbf{1 7 , 6 2}$ a & $\mathbf{1 6 , 3 7}$ a & $\mathbf{1 4 , 3 7} \mathbf{b}$ & $\mathbf{1 6 , 1 2}$ \\
\hline
\end{tabular}

*Her bölüm içinde aynı harfi gösteren ortalamalar arasındaki fark önemli değildir $(\mathrm{p}<0.05)$. 
Interactions and 95,0 Percent LSD Intervals

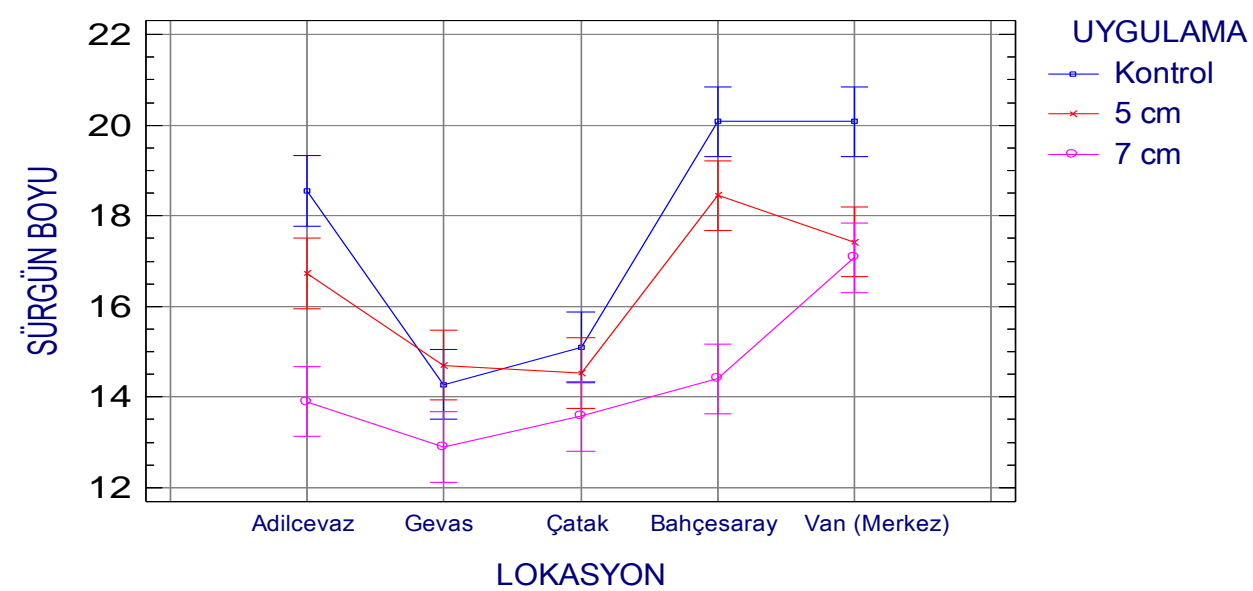

Şekil 2. . Lokasyon ve Uygulamalara göre Sürgün Boyu (cm) oranları

\section{Kök Çapı}

Yapılan çalışmada deneme faktörlerinden lokasyon ve uygulamalar kök çapı oranları üzerine etkileri istatistiksel olarak önemli olduğu belirlenmiştir $(\mathrm{P}<0.05)$. En yüksek kök çapı Gevaş yöresine ait cevizlerden elde edilmiştir $(13,92)$. Uygulamaların kök çapı oranı üzerine en olumlu sonucu 13,72 mm ile kontrol uygulaması olmuş onu radisilin $7 \mathrm{~cm}$ 'den kesimi uygulaması 12,96 mm ile takip etmiştir. Lokasyon ve uygulama interaksiyonunda Çatak+kontrol 14,42 mm değeri ile öne çıkmıştır. Her bir uygulamanın kendi içinde ortaya koymuş olduğu performans Çizelge 5 ve Şekil 3 'te sunulmuştur. Kök çapı üzerinde lokasyonlar açısından Gevaş, uygulamalar açısından Kontrol grubu öne çıkmıştır.

Çizelge 5. Lokasyon ve Uygulamalara göre Kök Çapı (mm) oranları

\begin{tabular}{|c|c|c|c|c|}
\hline Lokasyonlar & Kontrol & $\begin{array}{c}\text { Uygulamalar } \\
5 \text { cm'den Kesim }\end{array}$ & 7 cm'den Kesim & Ortalama \\
\hline 1-Adilcevaz & 13,59 & 13,14 & 13,33 & 13,35 ab \\
\hline 2- Gevaş & 14,11 & 13,68 & 13,98 & 13,92 a \\
\hline 3-Çatak & 14,42 & 11,75 & 11,93 & $12,70 \mathrm{bc}$ \\
\hline 4-Bahçesaray & 12,21 & 11,81 & 12,93 & $12,32 \mathrm{c}$ \\
\hline 5-Van (Merkez) & 14,26 & 14,02 & 12,66 & 13,65 ab \\
\hline Ortalama & 13,72 a & $12,88 \mathrm{~b}$ & $12,96 \mathrm{~b}$ & 13,19 \\
\hline
\end{tabular}

*Her bölüm içinde aynı harfi gösteren ortalamalar arasındaki fark önemli değildir $(\mathrm{p}<0.05)$. 
Interactions and 95,0 Percent LSD Intervals

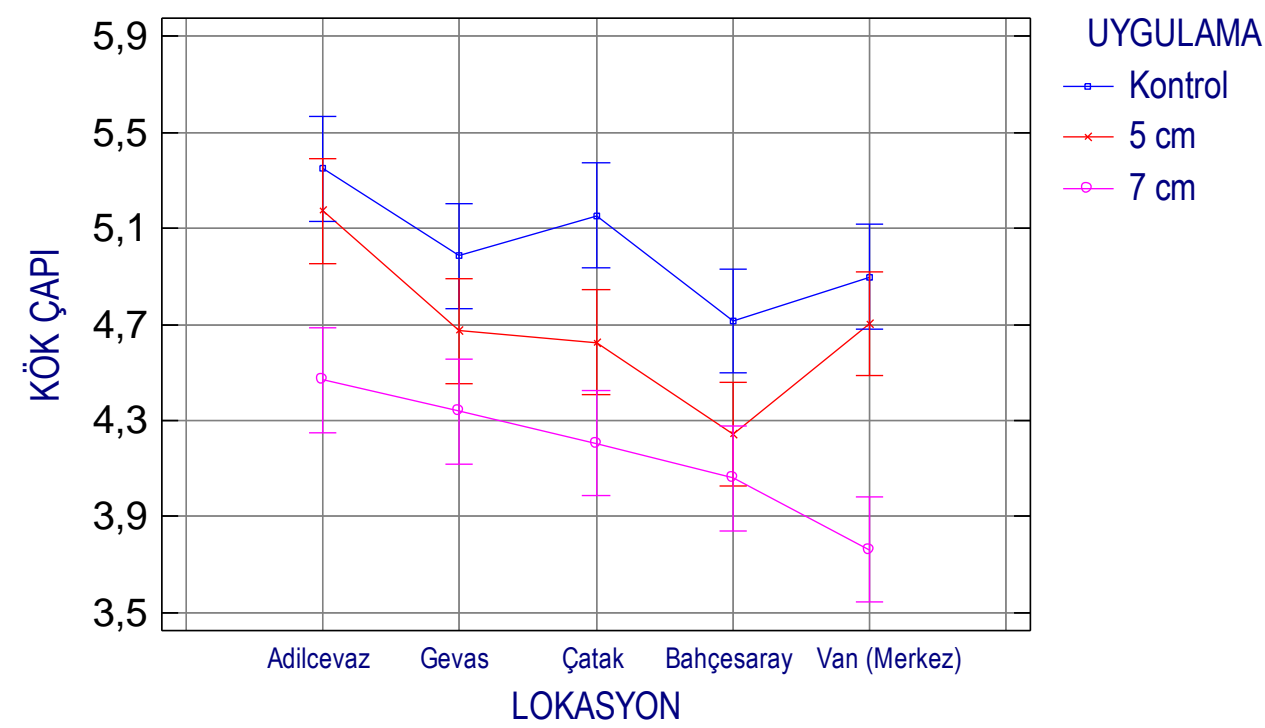

Şekil 3. Lokasyon ve Uygulamalara göre Kök Çapı (mm) oranları

\section{En Uzun Saçak Kök Uzunluğu}

Yapılan çalışmada deneme faktörlerinden lokasyon ve uygulamalar en uzun saçak kök uzunluğu oranları üzerine etkileri istatistiksel olarak önemli olduğu belirlenmiştir $(\mathrm{P}<0.05)$. En yüksek en uzun saçak kök uzunluğu Gevaş yöresine ait cevizlerden elde edilmiştir $(30,00)$. Uygulamaların en uzun saçak kök uzunluğu oranı üzerine en olumlu sonucu $32,45 \mathrm{~mm}$ ile radisilin $7 \mathrm{~cm}$ 'den kesimi uygulaması vermiştir. Lokasyon ve uygulama interaksiyonunda Adilcevaz $+7 \mathrm{~cm}$ 'den kesim $36,25 \mathrm{~cm}$ değeri ile öne çıkmıştır. Her bir uygulamanın kendi içinde ortaya koymuş olduğu performans Çizelge 6 ve Şekil 4 'te sunulmuştur. En uzun saçak kök uzunluğu üzerinde lokasyonlar açısından Gevaş, uygulamalar açısından 7 cm'den kesim grubu öne çıkmıştır.

Çizelge 6. Lokasyon ve uygulamalara göre en uzun saçak kök uzunluğu $(\mathrm{cm})$ oranları

\begin{tabular}{|c|c|c|c|c|}
\hline Lokasyonlar & Kontrol & $\begin{array}{c}\text { Uygulamalar } \\
5 \text { cm'den Kesim }\end{array}$ & 7 cm'den Kesim & Ortalama \\
\hline 1-Adilcevaz & 21,00 & 27,75 & 36,25 & $28,33 \mathrm{ab}$ \\
\hline 2- Gevaş & 26,00 & 28,00 & 36,00 & 30,00 a \\
\hline 3-Çatak & 17,00 & 24,00 & 28,50 & $23,17 \mathrm{c}$ \\
\hline 4-Bahçesaray & 21,50 & 27,00 & 31,00 & $26,50 \mathrm{~b}$ \\
\hline 5-Van (Merkez) & 23,50 & 26,75 & 30,50 & 26,92 b \\
\hline Ortalama & $21,80 \mathrm{c}$ & 26,70 b & 32,45 a & 26,98 \\
\hline
\end{tabular}

*Her bölüm içinde aynı harfi gösteren ortalamalar arasındaki fark önemli değildir ( $<<0.05)$. 


\section{Interactions and 95,0 Percent LSD Intervals}

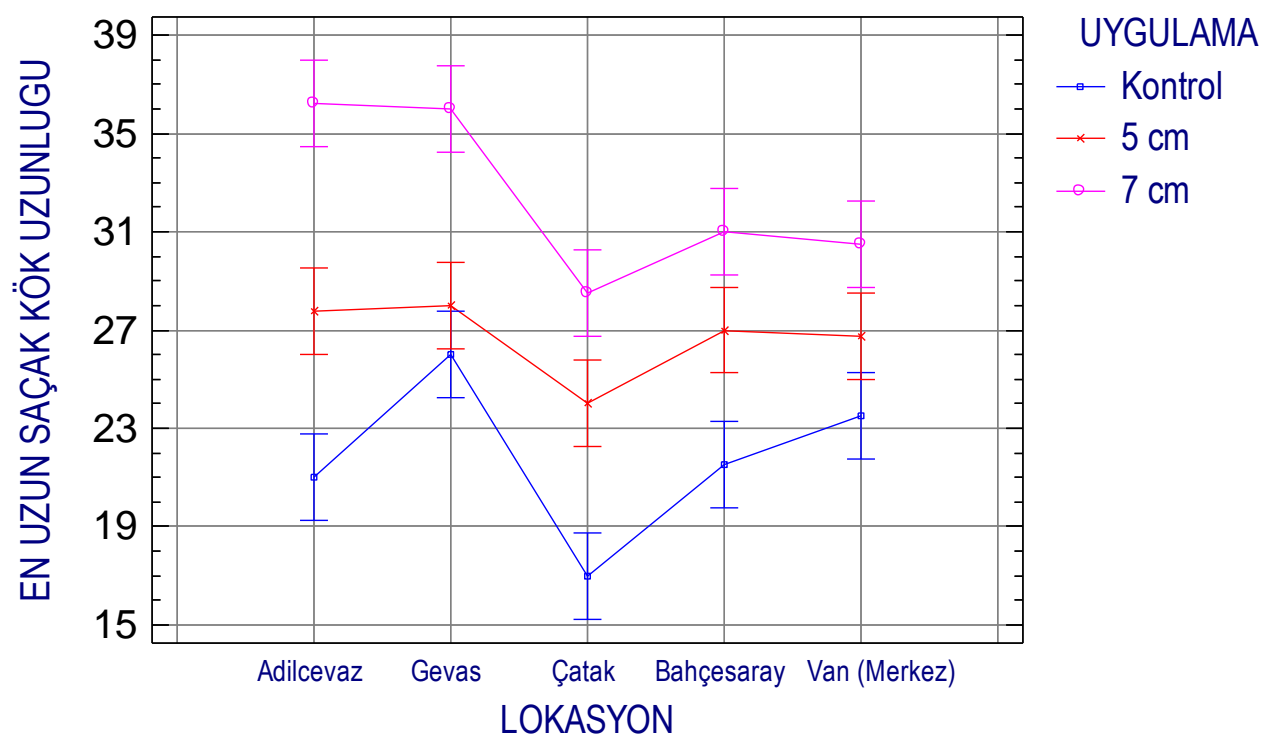

Şekil 4. Lokasyon ve uygulamalara göre en uzun saçak kök uzunluğu (cm) oranları

\section{Saçak Kök Sayısı}

Lokasyonlar arasında, kök sayısı bakımından oluşan farkların istatistiksel olarak önemli olmadığı uygulamalar açısından önemli olduğu belirlenmiştir $(\mathrm{P}<0.05)$. Kök sayısı bakımında denemedeki lokasyonlar aynı grupta toplanmıştır. Uygulamaların kök sayısı üzerine en olumlu sonucu ortalamalar bazında 32,00 adet ile radisilin $7 \mathrm{~cm}$ 'den kesimi uygulaması vermiştir. Lokasyon ve uygulama interaksiyonunda Gevaş+7 cm'den kesim 33 adet değeri ile öne çıkmıştır. Her bir uygulamanın kendi içinde ortaya koymuş olduğu performans Çizelge 7 ve Şekil 5'de sunulmuştur. Kök sayısı üzerinde uygulamalar açısından $7 \mathrm{~cm}$ 'den kesim grubu öne çıkmıştır.

Çizelge 7. Lokasyon ve uygulamalara göre en uzun saçak kök sayısı (adet)

\begin{tabular}{lcccc}
\hline \multicolumn{1}{c}{ Lokasyonlar } & \multicolumn{4}{c}{ Uygulamalar } \\
& Kontrol & $\mathbf{5} \mathbf{c m}$ den Kesim & $\mathbf{7 ~ c m}$ den Kesim & Ortalama \\
\hline 1-Adilcevaz & 25,75 & 26,25 & 31,50 & $\mathbf{2 7 , 8 3} \mathbf{a}$ \\
2- Gevaş & 25,00 & 27,75 & 33,00 & $\mathbf{2 8 , 5 8} \mathbf{a}$ \\
3-Çatak & 24,00 & 27,25 & 31,25 & $\mathbf{2 7 , 5 0} \mathbf{a}$ \\
4-Bahçesaray & 30,00 & 27,00 & 32,00 & $\mathbf{2 9 , 6 7} \mathbf{a}$ \\
5-Van (Merkez) & 25,75 & 26,25 & 32,25 & $\mathbf{2 8 , 0 8} \mathbf{a}$ \\
\hline Ortalama & $\mathbf{2 6 , 1 0 ~ b}$ & $\mathbf{2 6 , 9 0} \mathbf{~ b}$ & $\mathbf{3 2 , 0 0}$ a & 28,33 a \\
\hline
\end{tabular}

*Her bölüm içinde aynı harfi gösteren ortalamalar arasındaki fark önemli değildir $(\mathrm{p}<0.05)$. 


\section{Interactions and 95,0 Percent LSD Intervals}

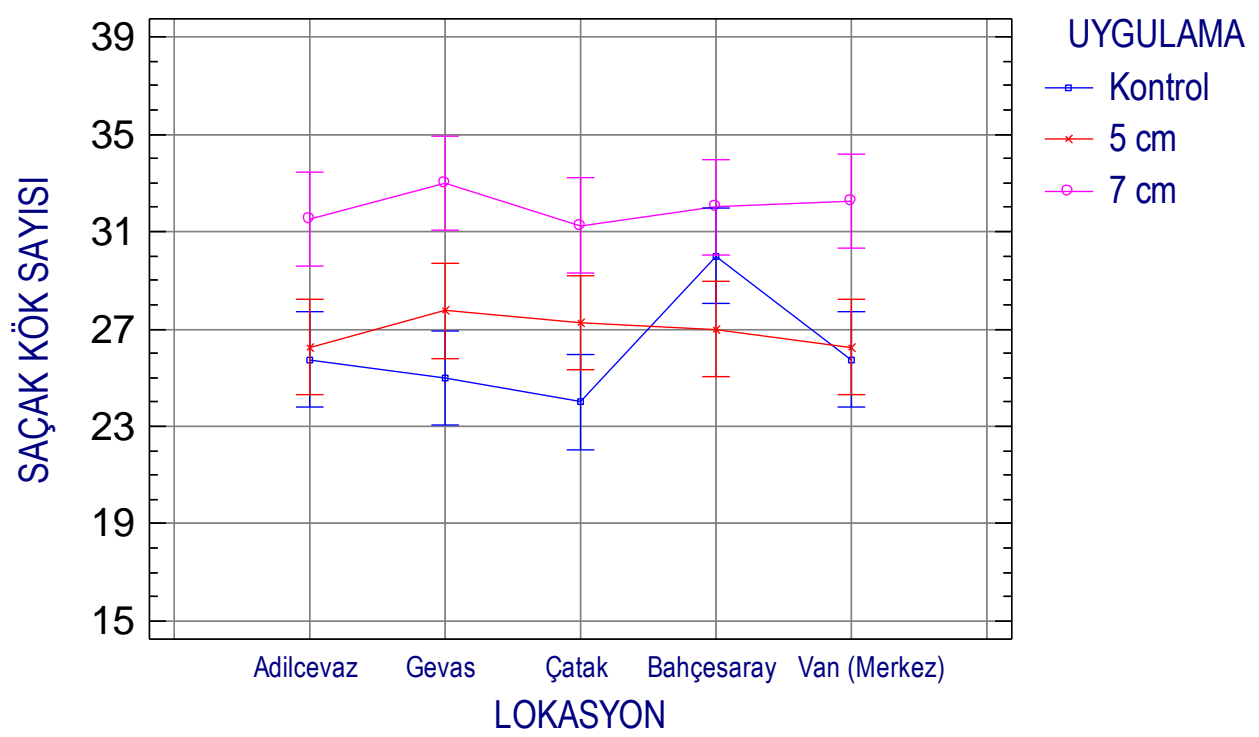

Şekil 5. Lokasyon ve uygulamalara göre en uzun saçak kök sayısı (adet)

Yaprak Sayıs

Uygulamalar ve lokasyon/uygulama interaksiyonlarının yaprak sayısı oranı bakımından oluşan farkların istatistiksel olarak önemli olduğu belirlenmiştir $(\mathrm{P}<0.05)$. En yüksek yaprak sayısı Çatak ve Adilcevaz yöresine ait cevizlerden elde edilmiştir (9,25-9,17 adet). Uygulamaların yaprak sayısı üzerine en olumlu sonucu 10,05 adet ile radisilin $7 \mathrm{~cm}$ 'den kesimi uygulaması vermiştir. Lokasyon ve uygulama interaksiyonunda Bahçesaray+7 cm'den Kesim 11,50 adet değeri ile öne çıkmıştır. Her bir uygulamanın kendi içinde ortaya koymuş olduğu performans Çizelge 8 ve Şekil 6'da sunulmuştur. yaprak sayıs1 üzerinde lokasyonlar açısından Adilcevaz, uygulamalar açısından $7 \mathrm{~cm}$ 'den kesim grubu öne çıkmıştır.

Çizelge 8. Lokasyon ve uygulamalara göre yaprak sayısı (adet)

\begin{tabular}{lcccc}
\hline \multicolumn{1}{c}{ Lokasyonlar } & \multicolumn{4}{c}{ Uygulamalar } \\
& Kontrol & $\mathbf{5} \mathbf{c m}$ den Kesim & $\mathbf{7} \mathbf{~ c m}$ den Kesim & Ortalama \\
\hline 1-Adilcevaz & 11,00 & 6,75 & 9,75 & $\mathbf{9 , 1 7} \mathbf{a}$ \\
2- Gevaş & 9,00 & 6,50 & 9,50 & $\mathbf{8 , 3 3} \mathbf{~ a b}$ \\
3-Çatak & 11,00 & 6,25 & 10,50 & $\mathbf{9 , 2 5} \mathbf{a}$ \\
4-Bahçesaray & 6,75 & 5,50 & 11,50 & $\mathbf{7 , 9 2} \mathbf{b}$ \\
5-Van (Merkez) & 10,00 & 5,50 & 9,00 & $\mathbf{8 , 1 7} \mathbf{a b}$ \\
\hline Ortalama & $\mathbf{9 , 5 5} \mathbf{a}$ & $\mathbf{6 , 1 0} \mathbf{b}$ & $\mathbf{1 0 , 0 5} \mathbf{a}$ & 8,57 \\
\hline
\end{tabular}

*Her bölüm içinde aynı harfi gösteren ortalamalar arasındaki fark önemli değildir $(\mathrm{p}<0.05)$. 


\section{Interactions and 95,0 Percent LSD Intervals}

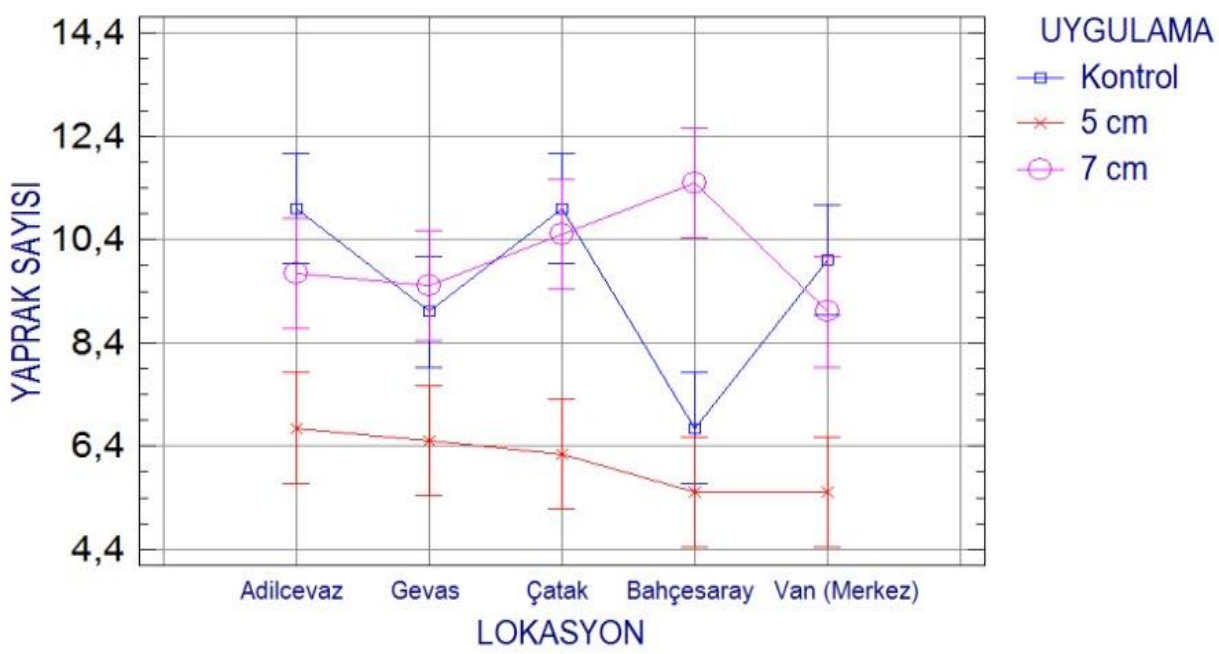

Şekil 6. Lokasyon ve uygulamalara göre yaprak sayısı (adet).

\section{Tartışma ve Sonuç}

Tüpe aktarılan ceviz çöğürlerinde, gövde uzunluğu ve yaprak sayısı ölçümlerinde, kontrol grubunda daha iyi gelişme olduğu saptanmıştır. Çimlenme ortamına dikilen çöğürlerde de, en uzun saçak kök uzunluğu ve saçak kök sayısı açısından, 7 cm'den kesim yapılan grubun çöğürlerinin daha iyi sonuçlar verdiği belirlenmiştir.

Çizelge 9. Lokasyonlar ve uygulamalarda (Ortalama Değerler) üzerinden öne çıkan uygulama ve bölgeler

\begin{tabular}{|c|c|c|c|c|c|c|c|c|c|}
\hline $\begin{array}{l}\text { İncelenen } \\
\text { Parametreler }\end{array}$ & $\begin{array}{c}\text { Kontrol } \\
\text { (0) }\end{array}$ & $\begin{array}{c}5 \mathrm{~cm} \\
(5)\end{array}$ & $\begin{array}{c}7 \mathrm{~cm} \\
(7)\end{array}$ & $\begin{array}{c}\text { Adilcevaz } \\
\text { (1) }\end{array}$ & $\begin{array}{c}\text { Gevaş } \\
(2)\end{array}$ & $\begin{array}{c}\text { Çatak } \\
(3)\end{array}$ & $\begin{array}{c}\text { Bahçesaray } \\
\text { (4) }\end{array}$ & $\begin{array}{c}\text { Van } \\
\text { (Merkez) } \\
(5)\end{array}$ & $\begin{array}{l}\text { Lokasyon / } \\
\text { Uygulama }\end{array}$ \\
\hline Gövde Çapı & 9,20 & - & - & 9,22 & - & - & - & 9,07 & $1 / 0(10,95)$ \\
\hline Sürgün Boyu & 17,62 & 16,37 & - & - & - & - & 17,64 & 18,19 & $\begin{array}{l}4 / 0-5 / 0 \\
(20,08)\end{array}$ \\
\hline Kök Çapı & 13,71 & - & - & - & 13,92 & - & - & - & $3 / 0(14,42)$ \\
\hline $\begin{array}{l}\text { En Uzun } \\
\text { Saçak Kök } \\
\text { Uzunluğu }\end{array}$ & - & - & 32,45 & - & 30,0 & - & - & - & $1 / 7(36,25)$ \\
\hline $\begin{array}{l}\text { Saçak Kök } \\
\text { Sayısı }\end{array}$ & - & - & 32,0 & 27,83 & 28,58 & 27,5 & 29,67 & 28,08 & $2 / 7(33,0)$ \\
\hline Yaprak Sayısı & 9,55 & - & 10,05 & 9,17 & - & 9,25 & - & - & $4 / 7(11,5)$ \\
\hline
\end{tabular}

Çizelge 10. Lokasyonlar ve uygulamalara ait analiz sonuçlarına göre F değerleri

\begin{tabular}{lccc}
\hline & A:LOKASYON & B:UYGULAMA & A/B \\
\hline Gövde Çapı (mm) & $13.90^{*}$ & $27.65 *$ & $5.09 *$ \\
Sürgüm Boyu (cm) & $36,40 *$ & $45,42 *$ & $4,07 *$ \\
Kök Çapı (mm) & $8,07 *$ & $39,52 *$ & $1,14 \mathrm{~ns}$ \\
En Uzun Saçak Kök (cm) & $12,66 *$ & $93,25 *$ & $2,12 \mathrm{~ns}$ \\
Saçak Kök Sayısı (adet) & $1,15 \mathrm{~ns}$ & $27,52 *$ & $1,08 \mathrm{~ns}$ \\
Yaprak Sayısı (adet) & $1,96 \mathrm{~ns}$ & $41,22 *$ & $2,96 *$ \\
\hline
\end{tabular}

Çizelge 9-10 incelendiğinde, uygulamalar dikkate alındığında, kontrol grubunda olan çöğürlerin genel olarak gövde çapı, sürgün boyu, kök çapı ve yaprak sayısı açısından iyi performanslar göstermiştir. 7 cm'den kök ucu kesilen çöğ̈̈rlerde kök ile ilgili gelişim parametrelerinin (gövde çapı, en uzun saçak kök 
uzunluğu, saçak kök sayısı ve yaprak sayısı) daha iyi sonuçlar verdiği saptanmıştır. Alkan ve ark., (2015) yaptıkları bir çalışmada 10 cm'den radisil kesimi yapılan çögürlerin, kök çapı, en uzun saçak kök uzunluğu, saçak kök sayısı ve gövde uzunluğu parametrelerine ait değerlerin, diğer uygulamalara göre daha yüksek olduğunu saptamışlardır. Benzer bir çalışmada, kök ucunun kesilmesiyle elde edilen bitkiler, bol saçak kök oluşturmuş ve gövde çaplarının aşılama kalınlığına kısa sürede geldikleri görülmüştür (Kaşka ve ark. 1992). Yapılan başka bir çalışmada ise, çimlenmiş Pistacia vera tohumlarının IBA, bakteri, radisil uç kesimi ve bakteri+radisil uç kesimi ile muamelesi, çöğürlerde yan kök oluşumunda önemli artışa sebep olmuştur. Sadece radisil kesimi yapılan uygulamada, yan kök sayısı ortalama 5.3'e yükselmiştir (Orhan ve ark. 2007). Kök ucu kesimi ile saçak kök gelişimi teşvik edilmekte, çögürlerin gövde çapları artmakta, çögürlerin söküm işleri kolaylaşmakta, sökümden sonra canlı kalan çöğür oranı artmakta ve fidanların bakımı kolaylaşmaktadır (Akça ve Yıldız 1995). Çalışmamızda elde edilen sonuçlarla yukarıda farklı araştırıcıların rapor ettikleri sonuçlar birbirini destekler düzeydedir.

Çöğür performanslarında ceviz tohumun alındığı bölgenin etkili olduğu belirlenmiştir. Tohumların çimlenmesini olumlu ve olumsuz etkileyen birçok faktör bulunmaktadır. Çögür yetiştiriciliğinde kullanılacak tohumlar dolgun, içleri sağlam ve besin maddelerince zengin olmalıdır. Tam olgunlaşmamış tohumlar çögür yetiştiriciliğinde kesinlikle kullanılmamalıdır. Tohum alınacak damızlık ağaçlar belirlenmeli ve coğrafik bölge olarak tohumların orijinlerine önem verilmelidir. Lokasyon/Uygulama interaksiyonunda uygulama açısından kontrol uygulaması sürgün gelişimi parametreleri olarak sayabileceğimiz: gövde çap1, sürgün boyu, kök çap1 ve yaprak sayısı, kök kesimi yapılmayan kontrol uygulamasında en yüksek değerleri sağlamıştır. Alkan ve ark. (2015) yaptıkları bir çalışmada kontrol grubunda olan çögürlerin genel olarak sürgün gelişimleri ile ilgili iyi performanslar gösterdiği, ancak buna karşın 10 cm'den radisili kesilen çögüurlerde kök ile ilgili gelişim parametrelerinin daha iyi sonuçlar verdiğini saptamışlardır. Belirtilen parametreler elde etmiş olduğumuz bu değerlerle paralellik göstermektedir. Ceviz tohumlarının alındığı lokasyonlarda öne çıkan bölgeler Adilcevaz ve onu takiben Bahçesaray yöresinden alınan cevizlerin performansı diğer lokasyonlara göre daha iyi oldukları görülmüştür.

\section{Kaynaklar}

Ağaoğlu YS, Çelik H, Çelik M, Fidan Y, Gülşen, A. Günay, N. Halloran A, Köksal İ., Yanmaz R., (1997). Genel Bahçe Bitkileri. Ankara Üniversitesi Ziraat Fakültesi Eğitim, Araştırma ve Geliştirme Vakfi Yayınları No:4, Ankara.

Akça Y, Yıldız K (1995). Ceviz yetiştiriciliğinde saçak köklü tüplü çöğür ve fidan yetiştirme üzerine bir araştırma. 3-6 Ekim, 1995 Adana, Cilt 1 (Meyve):470-475. Türkiye II. Ulusal Bahçe Bitkileri Kongresi, (Tam Metin Bildiri) (Yayın No:966734)

Alkan G, Ertan E, Hekimci B, Algül BE (2015). Sert Kabuklu Meyve Türleri Tohumlarında Çimlenme Sonrasi Kök Kesimi Uygulamasının Çöğür Gelişimi Üzerine Etkisi. Adnan Menderes Üniversitesi Ziraat Fakültesi Dergisi, 12(1), 49-56.

Kaşka N, Yılmaz, M (1974). Bahçe bitkileri yetiştirme tekniği. Çukurova Üniversitesi Ziraat Fakültesi Yayınları, 79.

Kaşka N, Ak BE, Nikpeyma Y (1992). Antepfistığı yetiştiriciliğinde saçak köklü çöğür ve fidan yetiştirme üzerine bir araştırma. I.Ulusal Bahçe Bit. Kongresi Bildiriler Kitabı, s:89-92. İzmir.

Ko DS, Choi MB, (1975). Production of homogeneous walnut (Juglans sinensis) seedlings. Bull. Agr. Coll. Jeonbug Nat. Univ. Vol. 6 pp. 31-34.

Koyuncu F, Yıldız K, Tekintaş, E (1999). Cevizde (J. regia L.) Tohum Ağırlığının Çimlenme ve Çöğür Gelişimi Üzerine Etkisi. Türkiye III. Ulusal Bahçe Bitkileri Kongresi. 14-17 Eylül 1999, Ankara, 653-657 s.

Orhan E, Esitken A, Ercisli S, Sahin F (2007). Effects of indole-3-butyric acid (IBA), bacteria and radicle tip- cutting on lateral root induction in Pistacia vera. Journal of Horticultural Science and Biotechnology. Vol. 82 No. 1 pp. 2-4.

Sütyemez M, (2011). Bahçe Bitkileri Genel Meyvecilik Ders Notları (Yayımlanmamış).

Şen SM, Kazankaya A, Yarılgaç T, Doğan A. (2006). Bahçeden Mutfağa Ceviz. Maji Yayınları, 233s, Ankara. 